Article

\title{
Influence of Chemical Modifications of Polyhydroxyalkanoate-Derived Fatty Acids on Their Antimicrobial Properties
}

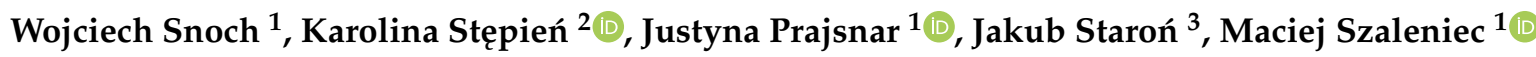 \\ and Maciej Guzik 1,*(D) \\ 1 Jerzy Haber Institute of Catalysis and Surface Chemistry, Polish Academy of Sciences, Niezapominajek 8, \\ 30-239 Kraków, Poland; ncsnoch@cyfronet.pl (W.S.); justyna.prajsnar1@gmail.com (J.P.); \\ ncszalen@cyfronet.pl (M.S.) \\ 2 Medical University of Warsaw, Department of Pharmaceutical Microbiology, 3 Oczki Str. 02-007 Warsaw, \\ Poland; Karolinastepien@windowslive.com \\ 3 Institute of Pharmacology, Polish Academy of Sciences, Smętna 12, 31-343 Kraków, Poland; \\ jakubstaron@gmail.com \\ * Correspondence: ncguzik@cyfronet.pl; Tel.: +48-126-395-155
}

Received: 15 May 2019; Accepted: 30 May 2019; Published: 5 June 2019

\begin{abstract}
Sugar esters are bioactive compounds derived from renewable resources. They consist of a sugar moiety with attached non-polar part - usually a fatty acid. These compounds find uses in cosmetic, food and pharmaceutical industries as surfactants due to their physicochemical and antimicrobial activities. In this study we have produced fatty acids for sugar ester synthesis from bacterially derived polyesters, namely polyhydroxyalkanoates (PHAs). We have developed methodology to decorate PHA monomers with a fluorinated moiety. With aid of biocatalysis a series of glucose esters was created with unmodified and modified PHA monomers. All synthesised compounds showed moderate antimicrobial activity.
\end{abstract}

Keywords: polyhydroxyalkanoate; (R)-3-hydroxyacids; biocatalysis; sugar esters; antimicrobial

\section{Introduction}

Sugar esters represent a class of biodegradable and bioactive compounds that brought attention of scientists and industries in recent decades [1]. These molecules are composed of a hydrophilic sugar component (rich in hydroxyl groups) connected via ester bonds to a hydrophobic part, usually a carboxylic acid. The number and the length of these acid derived chains, together with the number of hydroxyl groups of the particular sugar determine the hydrophilic-lipophilic balance (HLB) - a unique property of a given molecule of sugar ester. At the same time their chemical structures enable them to form micelles, emulsions, stabilize foams thanks to their surface active properties [2,3]. These features bring practical importance of sugar fatty acids esters (SFAEs), hence they are widely used in the food, cosmetic and pharmaceutical industries (as additives for dairy products, feeds, creams, gels, shampoos, pastes, ointments) [3-7]. SFAE not only have interesting physicochemical properties, but also are biologically active $[8,9]$, increase the cell membrane permeability of microorganisms and inactivate transmembrane proteins, thus exposing microbes to adverse external factors, loss of intracellular proteins and valuable nutrients leading to an immediate inactivation $[10,11]$.

The most popular among the sugar esters are those which contain glucose, galactose, sucrose or lactose because of their availability from natural resources [12-16]. The hydrophobic component is commonly derived from plant or animal biomass, e.g., butyric (C4), caprylic (C8), pelargonic (C9), lauric (C12), palmitic (C16) and stearic (C18) acids [5,8,9,17,18]. Depending on the length of aliphatic 
chain, its branching and existence of additional functional groups SFAE molecules may be more or less available for a given organism (due to variations in cell membrane transfer) and also faster or slower decomposed by enzymes (lipases, glycosidases). The presence of additional functional groups in the aliphatic chain modifies both the physical properties and therapeutic effect of SFAE, thus enhancing its biological effectiveness and spectrum [19-22]. These include phenyl, hydroxyl, amino, hydroxyphenyl, methoxy-phenyl and halogen-containing moieties, e.g., phenyl-fluorine, or alkyl halides [23-26]. Out of the mentioned modifiers, the fluorine most profoundly alters the molecule's biological functions (i.e., increases the free-radical production; influences bio-retention due to increased hydrophobicity of a given molecule) [27-29].

In order to aid in the search for new modifiers of the hydrophobic component of SFAE we tapped into monomeric units that build bacterially derived polymers. Bacteria synthesise polyhydroxyalkanoates (PHAs) in response to unfavourable environmental conditions employing sophisticated biochemical apparatus [30]. PHAs are composed of 3-hydroxylated fatty acids, where the hydroxyl group is always in an absolute $R$ configuration [31]. Existence of this hydroxyl group on the carboxylic acid moiety opens interesting paths for modifications [32]. For example, it can be readily used to form an ether bond between oxygen atom and a halogenated alkyl group, which may influence their potential therapeutic effect. In recent years similar modifications of PHA monomers have been performed. However, they relied on the elimination of the hydroxyl group on chiral 3rd carbon atom and its exchange to 3-chloro, 3-fluorobenzyl, 3-bromo, 3-fluoro or amino group, which led to the loss of chirality of the molecule, but improved bacteriostatic properties [33,34].

Our study presents the development of a biocatalytic synthesis method for the preparation of unique glucose esters based on PHA derived monomers, namely mixtures of $(R)$-3-hydroxynonanoic and $(R)$-3-hydroxyheptanoic acids or $(R)$-3-hydroxy-5-phenylpentanoic and $(R)$-3-hydroxy-3-phenylpropionic acids arising from two types of PHA polymers obtained in bacterial fermentation process grown on, respectively, nonanoic or 5-phenylvaleric acids. The PHA derived acids were further functionalised with a 2,2,2-trifluoroethyl trifluoromethyl sulphate moiety. The virgin mixtures or their modified counterparts were attached to glucose via lipase mediated biocatalytic reaction in a water-free organic solvent systems. The resulting novel SFAEs were purified and characterised, and submitted to antimicrobial studies in order to elucidate their potential antimicrobial characteristics.

\section{Results and Discussion}

\subsection{Synthesis of Polyhydroxyalkanoates}

P. putida CA-3 was cultured on 5-phenylpentanoic acid ( $40 \mathrm{mM})$ in a shake flask for 5 days, which yielded $2.43 \mathrm{~g} / \mathrm{L}$ of cell dry weight (CDW) mass with $57 \%(w / w)$ of PHA. The extracted PHA polymer (PHPV) composed of (R)-3-hydroxy-5-phenylpentanoic and (R)-3-hydroxy-3-phenylpropionic acids in a 94:6 molar ratio. In case of polyhydroxynonanoate (PHN) fermentation, P. putida KT244 strain was grown on nonanoic acid and accumulated $71 \%$ of the polymer in CDW, while the molar ratio of obtained (R)-3-hydroxynonanoic and (R)-3-hydroxyheptanoic acid monomers was 7:3.

\subsection{Modification of PHA Monomers}

The procedure described in Section 3 allowed us to obtain $1.26 \mathrm{~g}$ ( $48.5 \%$ conversion) of a pure fraction of desired products $(3,4)-\mathrm{PHN}$ derived mixture of hydroxyacids methyl esters. Structural analysis ( ${ }^{1} \mathrm{H}$ NMR, MS) of compounds revealed that $3-\mathrm{OH}$ groups of PHN methyl esters were successfully protected (Figures S4 and S5 in Supplementary Material). Product 10 lost the methyl group during the ionization in MS, therefore it was identified as acid $\left([\mathrm{M}-\mathrm{H}]^{-} 255 \mathrm{~m} / \mathrm{z}\right)$ at retention time (Rt) of $2.3 \mathrm{~min}$. An analogous situation occurred with the shorter protected PHA monomer (product 11), $(227 \mathrm{~m} / \mathrm{z}, \mathrm{Rt}=1.9 \mathrm{~min})$. Additionally, we observed a fragmentation ion $(162.9 \mathrm{~m} / \mathrm{z})$, which, in accordance with the theoretical predictions of the fragmentation of compound 11 (Figure S5 in Supplementary Materials). The remaining chromatography fractions contained either dimers or trimers of $\mathbf{1 0 + 1 1}$ or 
their fluorinated counterparts. Unfortunately all trials for P3HPV derived fatty acid modifications ended without significant results. ${ }^{14} \mathrm{C}$ NMR confirmed that an etheric bond between $\mathrm{C}_{-} \mathrm{O}^{-}$at the $3 \mathrm{rd}$ carbon atom of the P3HPV monomer aliphatic chain and trifluorethyl group was created. However purity of the collected fractions was unsatisfying, thus not allowing us from further biocatalytic steps with the mixture of $34+35$. Results of all were gathered and summarized in Table 1.

Table 1. Summary of PHA modifications and their sugar esters synthesis.

\begin{tabular}{cc}
\hline Compound Number: & Conversion [\%]: \\
\hline $\mathbf{1 5}$ & 100 \\
$\mathbf{1 0 , 1 1}$ & 48.5 \\
$\mathbf{7 , 8}$ & 100 \\
$\mathbf{1 3 , 1 4}$ & n.c. \\
$\mathbf{2 6}$ & $42.1^{*}$ \\
$\mathbf{2 7 , 2 8}$ & $85^{*}$ \\
$\mathbf{2 9 , 3 0}$ & n.c. \\
$\mathbf{3 1}$ & $43.3^{*}$ \\
$\mathbf{3 2 , 3 3}$ & $78.7^{*}$ \\
$\mathbf{3 4 , 3 5}$ & n.c. \\
\hline
\end{tabular}

${ }^{*}$ Conversions calculated from glucose concentrations.

To the best of our knowledge this is a first report that concerns protection of the hydroxyl group of a PHA monomers without its removal or its substitution by a halogen substituent [24,33-35]. NaH turned out to be an efficient reactant for hydrogen atoms removal of $\mathrm{PHN} 3-\mathrm{OH}$ groups and their activation for an attack of trifluoroethyl moiety, even though lithium diisopropylamide is a much stronger nucleophil. Most importantly, an extra dry THF as a medium turned out to be the key element of the whole synthetic process.

Conversion of glucose to its corresponding esters (SFAE) via Thermomyces lanuginosus lipase (TL-IM) was confirmed by MS/MS analysis (Table 2). Compound $\mathbf{2 6}$ was identified as $\left[\mathrm{M}+\mathrm{Cl}^{-}\right]^{-}$adduct $355 \mathrm{~m} / \mathrm{z}$ in a scan mode, whereas in Product Ion Scan mode its precursor $[\mathrm{M}-\mathrm{H}]^{-}$ion $(319 \mathrm{~m} / \mathrm{z})$ produced fragmentation ion $228.9 \mathrm{~m} / \mathrm{z}$ (Figure $\mathrm{S} 6$ in Supplementary Materials). PHN glucose esters $(\mathbf{2 7 , 2 8 )}$ - both $\mathrm{C} 9$ and $\mathrm{C} 7$ were detected as $\left[\mathrm{M}+\mathrm{Cl}^{-}\right]^{-}$ions in the scan mode, where their signals were 371 and $343 \mathrm{~m} / \mathrm{z}$ respectively. In Product Ion Scan mode the precursor and fragmentation ions were observed at 335 and $307 \mathrm{~m} / \mathrm{z}$. Compound 27 in Product Ion Scan was characterized by fragmentation signals at 334.7, 172.8, $58.7 \mathrm{~m} / \mathrm{z}$. Such fragmentation was consistent with results of the theoretical analysis of the breakdown of the compound (Figures S7 and S8 in Supplementary Materials). Glucose esters of aromatic compounds have been synthesized with success, as indicated by their spectra in MS analysis. The product 31 was detected as the $[\mathrm{M}-\mathrm{H}]^{-}$ion $(339 \mathrm{~m} / \mathrm{z})$. In the case of PHPV sugar esters, only the MS spectrum with (R)-3-hydroxy-5-phenylpentanoic acid (compound 33) was obtained. The compound was detected in the scan mode as the mass with the chlorine adduct, $\left(\left[\mathrm{M}+\mathrm{Cl}^{-}\right]^{-}=391 \mathrm{~m} / \mathrm{z}\right)$ with retention time of $1.4 \mathrm{~min}$. In Product Ion Scan mode the 33 precursor ion $[\mathrm{M}-\mathrm{H}]^{-}(355 \mathrm{~m} / \mathrm{z})$ did not fragmented within the range of scanned energy collisions. The yield obtained within our study are comparable to these obtained for acylation of glucose by others [36,37].

\subsection{Antimicrobial Testing}

The initial microbial experiment showed that MIC (or Minimum bactericidal concentration-MBC) values of both unmodified and modified PHA monomers and their glucose esters are in most cases higher than $500 \mu \mathrm{g} \mathrm{mL}^{-1}$, which is 50,000 fold higher than commonly used antibiotics (Ciplofloxan, Fluxonazole) [38,39]. Nevertheless, the literature reports and our results show that SFAEs in general have a bacteriostatic effect if present in higher concentrations, which can be used for other than therapeutic purposes (e.g., in the cosmetic or food industries, as surfactants/emulsifiers) [20,21,40,41]. Therefore, we increased the tested concentrations up to $5000 \mu \mathrm{g} \mathrm{mL}^{-1}$ (Table 3). 
Table 2. Precursor ions and Product ions of tested compounds in product ion scan mode.

\begin{tabular}{ccccc}
\hline Compound & Precursor Ion $(\boldsymbol{m} / \mathbf{z})$ & Product Ions $(\mathrm{m} / \mathbf{z})$ & Collision Energies $(\mathbf{e V})$ & Retention Time $(\mathbf{m i n})$ \\
\hline $\mathbf{1}$ & 157 & 157.1 & 5 & 1.6 \\
$\mathbf{3}$ & 173 & $173.1,59$ & 5 & 1.9 \\
$\mathbf{4}$ & 145 & $145.1,59$ & 5 & 1.8 \\
$\mathbf{5}$ & 191 & $114.8,190.6$ & 5 & 1.6 \\
$\mathbf{7}$ & 207 & $176.9,206.9$ & 5 & 1.6 \\
$\mathbf{8}$ & 179 & n.c & - & - \\
$\mathbf{1 2}$ & 255 & 255 & 5 & 2.3 \\
$\mathbf{1 3}$ & 227 & $226.7,162.9$ & 5 & 1.9 \\
$\mathbf{2 6}$ & 319 & $318.5,228.9$ & 5 & 1.7 \\
$\mathbf{2 7}$ & 335 & $334.7,172.8,58.7$ & 10 & 1.4 \\
$\mathbf{2 8}$ & 307 & n.c. ${ }^{*}$ & - & - \\
$\mathbf{2 9}$ & 417 & 417.1 & 25 & 1.6 \\
$\mathbf{3 0}$ & 389 & n.c & - & - \\
$\mathbf{3 1}$ & 339 & 338.9 & 5 & 1.7 \\
$\mathbf{3 3}$ & 356 & 354.9 & 5 & 1.4 \\
$\mathbf{3 2}$ & n.c. & n.d. ${ }^{*}$ & - & - \\
\hline
\end{tabular}

The results obtained during this study prove that microorganisms exhibit different sensitivity to antimicrobial agents, which strongly depends on the type of carbohydrate used, length of fatty acids attached to the sugar and moiety linked to the fatty acid part of SFAE. 5-phenylvaleric acid proved to be more effective against the tested bacteria at lower concentrations compared to aliphatic nonanoic acid. The antibacterial action of acids with the phenyl group has been known before-phenylpropionic or phenylacetic acid have a strong antibacterial effect on various types of bacteria such as S. aureus, C. albicans and E. coli at $1000 \mu \mathrm{g} \mathrm{mL}^{-1}$ [42]. The opposite situation was observed in the case of inhibition of Candida growth, where nonanoic acid was more effective at 10 times lower concentrations compared to aromatic acids [43]. It has been reported that nonanoic acid could be active against some dermatophytes and non-dermatophyte fungi. Some of other saturated fatty acids (i.e., capric and lauric) have been also reported to possess the inhibitory effect against Candida spp. Fungicidal activity of fatty acids could be determined by mechanisms focused on yeast membrane disruption [43]. Sugar fatty acids esters also tend to be biologically beneficial in combating fungi. Their emulsifying properties could be successful implement in detergents and cosmetic production.

PHA monomers with a hydroxyl group at the 3rd carbon atom showed a stronger antibacterial activity (for bacteria strain such as Staphylococcus aureus NCTC 4163 and Bacillus cereus ATCC 11778), when compared to their fatty acids analogues without the 3-OH group. Similar results were obtained by Sandoval and colleagues, who tested the effect of the hydroxyl group on the antibacterial properties of PHA monomers [44]. For other strains tested no improvement of antibacterial activity was observed in the MIC between 5-phenylvaleric acid and PHPV derived monomer mixture. Attachment of the fluorinated moiety to PHN derived monomers did not significantly influenced their biological activity against tested strains. 


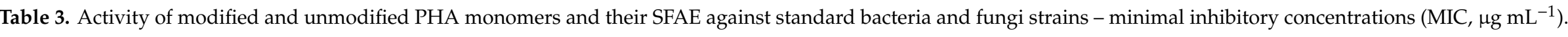

\begin{tabular}{|c|c|c|c|c|c|c|c|c|c|c|c|}
\hline $\begin{array}{l}\text { Ciprofloxacin/ } \\
\text { Fluxonazole }\end{array}$ & {$[34,35]$} & {$[32,33]$} & {$[27,28]$} & [31] & [26] & {$[10,11]$} & {$[7,8]$} & {$[3,4]$} & [5] & [1] & Compound [ug mL $\mathrm{m}^{-1}$ ]: \\
\hline 4 & 2500 & $>5000$ & 2500 & 5000 & 5000 & 2500 & 2500 & 1250 & 1250 & 2500 & Staphylococcus aureus NCTC 4163 \\
\hline 0.5 & 5000 & $>5000$ & 1250 & $>5000$ & 5000 & 2500 & 2500 & 2500 & 1250 & 2500 & Staphylococcus aureus ATCC 6538 \\
\hline 0.5 & 5000 & $>5000$ & 1250 & $>5000$ & 5000 & 2500 & 1250 & 2500 & 1250 & 2500 & Staphylococcus epidermidis RP 62A \\
\hline 0.5 & $>5000$ & $>5000$ & $>5000$ & $>5000$ & 5000 & 2500 & 2500 & 2500 & 2500 & 2500 & Enterococcus hirae ATCC 10541 \\
\hline 0.5 & $>5000$ & $>5000$ & $>5000$ & $>5000$ & 2500 & 2500 & 2500 & 1250 & 1250 & 2500 & Bacillus cereus ATCC 11778 \\
\hline 0.5 & $>5000$ & $>5000$ & $>5000$ & $>5000$ & 5000 & 2500 & 2500 & 2500 & 1250 & 2500 & Bacillus subtilis ATCC 6633 \\
\hline 0.5 & $>5000$ & $>5000$ & $>5000$ & $>5000$ & $>5000$ & 5000 & 5000 & 5000 & 2500 & 5000 & Pseudomonas aeruginosa ATCC 27853 \\
\hline 0.5 & $>5000$ & $>5000$ & $>5000$ & $>5000$ & 5000 & 2500 & 2500 & 5000 & 2500 & 2500 & $\begin{array}{l}\text { Salmonella enterica subsp. fnterica CIP } \\
108115\end{array}$ \\
\hline 0.5 & $>5000$ & $>5000$ & 5000 & $>5000$ & 5000 & 2500 & 1250 & 2500 & 2500 & 2500 & Listeria monocytogenes \\
\hline 0.5 & $>5000$ & $>5000$ & $>5000$ & $>5000$ & 313 & 5000 & $>5000$ & $>5000$ & 625 & 156 & Candida parapsilosis ATCC 22019 \\
\hline 0.5 & $>5000$ & $>5000$ & $>5000$ & $>5000$ & 625 & 5000 & $>5000$ & 2500 & 1250 & 313 & Candida albicans ATCC 90028 \\
\hline 0.5 & $>5000$ & $>5000$ & $>5000$ & $>5000$ & 625 & $>5000$ & $>5000$ & 5000 & 1250 & 156 & Candida krusei ATCC 6258 \\
\hline 0.5 & $>5000$ & $>5000$ & $>5000$ & $>5000$ & 1250 & 5000 & $>5000$ & 5000 & 1250 & 156 & Candida albicans ATCC 10231 \\
\hline
\end{tabular}


Sugar esters synthetized in this work revealed weak antibacterial to moderate antifungal activities (Table 3). C9-glucose ester (26) exhibited the highest antifungal activity of all studied sugar esters (MIC values of 313; 625; $625 \mu \mathrm{g} \mathrm{mL} \mathrm{m}^{-1}$ for C. parapsilosis; C. albicans ATCC 90028; C. crusei ATCC 1023, respectively). We observed also some antibacterial activity of PHN glucose esters $(27,28)$ towards Staphylococcus spp. in MIC range of $1250-2500 \mu \mathrm{g} \mathrm{mL}^{-1}$. When modified with fluorine moiety, the PHN derived esters $(34,35)$ retained their antimicrobial activity for Staphylococcus aureus NCTC 4163 (MIC $2500 \mu \mathrm{g} \mathrm{mL}^{-1}$ ). For other tested pairs (glucose esters vs. tested strain) we did not observe significant antimicrobial action. These findings are in line with reports of others, where glucose or maltose sugar esters (fatty acid carbon atoms $\mathrm{n}=8-14$ ) revealed MIC values between 250 to $2000 \mu \mathrm{g} \mathrm{mL}^{-1}$, when tested against a range of Gram negative and positive strains [10,45].

\section{Materials and Methods}

\subsection{Synthesis of Polyhydroxyalkanoates}

Polyhydroxynonanoate (PHN; 2) was produced with Pseudomonas putida KT2440 strain with nonanoic acid (1) in the fermentation feed as the sole energy and carbon source (Figure 1A) as described in our previous study [46]. Polyhydroxyphenylvalerate (PHPV; 6, Figure 1B) was obtained in shake flask cultures with Pseudomonas putida CA-3 ( $50 \mathrm{~mL}$ total medium volume in $250 \mathrm{~mL}$ Erlenmeyer flasks, $30^{\circ} \mathrm{C}$, $250 \mathrm{rpm}, 5$ day fed-batch cultivation) in Minimal Salt Medium (containing $\left(\mathrm{g} \mathrm{L}^{-1}\right)$ : $\mathrm{Na}_{2} \mathrm{HPO}_{4} \cdot 12 \mathrm{H}_{2} \mathrm{O}$, 9.0; $\mathrm{KH}_{2} \mathrm{PO}_{4}, 1.5 ; \mathrm{MgSO}_{4} \cdot 7 \mathrm{H}_{2} \mathrm{O}, 0.2 ; \mathrm{NH}_{4} \mathrm{Cl}, 1.0 ; \mathrm{CaCl}_{2} \cdot 2 \mathrm{H}_{2} \mathrm{O}, 0.02 ; \mathrm{Fe}(\mathrm{III}) \mathrm{NH}_{4}$-citrate, 0.0012) with sodium phenylvalerate (total $80 \mathrm{mM}$ ). Polymers were extracted with ethyl acetate and characterised as described previously [46]. The polymers were degraded to their monomeric units via an acidic methanolysis $\left(15 \% \mathrm{H}_{2} \mathrm{SO}_{4}\right.$ in methanol) to yield hydroxy fatty acid methyl esters according to previously established protocol [34].

\subsection{Modification of PHA Monomers}

Several methods of the 3-OH PHA methyl esters groups' halogenation were tested. Briefly different fluorinated alkyl iodes (1-fluoro-3-iodopropane; 1,1-difluoro-2-iodoethane; 1,1,1-trifluoro-3-iodopropane), various nucleophiles (sodium hydride $(\mathrm{NaH} ; 60 \%$ ), lithium diisopropylamide (LDA)) and different media (dimethylformamide (DMF), dichloromethane (DCM), tetrahydrofuran (THF)) were tested. Finally one method was chosen and was as follows. To stirred solution of $2.26 \mathrm{~g}$ PHN (2; 1 eq. mol) in anhydrous THF $(20 \mathrm{~mL}), \mathrm{NaH}(1.2$ eq. mol) was added under

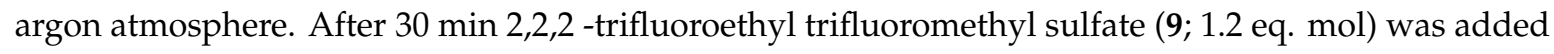
(Figure 1C). The reaction mixture was stirred on ice overnight. After acidification, an extraction in ethyl acetate (Et-Ac)/ $\mathrm{H}_{2} \mathrm{O}$ was performed. TLC in Ac 1:7 $\mathrm{H}$ confirmed that no PHN (2) was left in the reaction mixture. Versa flash chromatography purification gave fraction of $1.5 \mathrm{~g}$ fluorinated PHN methyl esters $(\mathbf{1 0 , 1 1})$ mixture $\left({ }^{1} \mathrm{H}\right.$ NMR spectra are available in supplementary materials). PHPV modification followed under the same procedure (Figure 1D). After modifications a part of all of the obtained monomers was converted into their acidic forms using Candida antractica lipase B (CalB) in water environment (Figure 1F,H). Briefly $300 \mathrm{mg}$ of a given methyl ester was dissolved in $2 \mathrm{~mL}$ of dichloromethane. To $5 \mathrm{~mL}$ of $\mathrm{H}_{2} \mathrm{O}, 85 \mathrm{mg}$ of lipase was added. Both mixtures were combined and vigorously shaken $\left(240 \mathrm{rpm}, 35^{\circ} \mathrm{C}\right)$ overnight. Mixtures were acidified to $\mathrm{pH} 4$ with $\mathrm{HCl}$, and brine was added followed by the addition of $7 \mathrm{~mL}$ of ethyl acetate in order to extract $(3 \times)$ the desired fatty acid.

\subsection{SFAE Synthesis}

Enzymatic reactions were carried out in water free 2-methyl-2-butanol (2M2B) in $10 \mathrm{~mL}$ total volume. Glucose was supplemented to yield $4 \mathrm{mg} \mathrm{mL}^{-1}$ (1 eq. mol), whereas methyl nonaoate (15) to $11 \mathrm{mg} \mathrm{mL}^{-1}$; PHN methyl esters $(\mathbf{3}, 4) 9.5 \mathrm{mg} \mathrm{mL}^{-1}$; fluorinated PHN methyl esters $(\mathbf{1 0 , 1 1}) 11.46$ $\mathrm{mg} \mathrm{mL}^{-1}$; 5-phenylpentanoic methyl esters (20) to $8.3 \mathrm{mg} \mathrm{mL}^{-1}$; PHPV methyl esters $(\mathbf{7}, 8) 9.02 \mathrm{mg}$

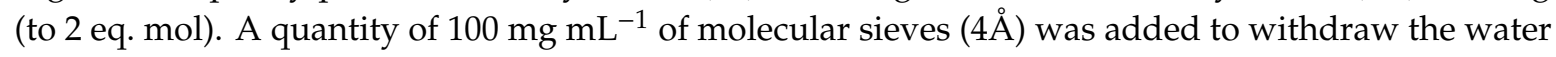


formed. Reactions were initiated by addition of $12 \mathrm{mg} \mathrm{mL}^{-1}$ of an enzyme (Thermomyces lanuginosus lipase herein referred to as TL-IM), with shaking $\left(240 \mathrm{rpm}\right.$ ), at $55^{\circ} \mathrm{C}$ for $24 \mathrm{~h}$ (New Brunswick Scientific Exella E24 Incubator Shaker Series; (Figure 2)) [36,37,47]. Samples were collected at set intervals and were analysed on HPLC-MS system.

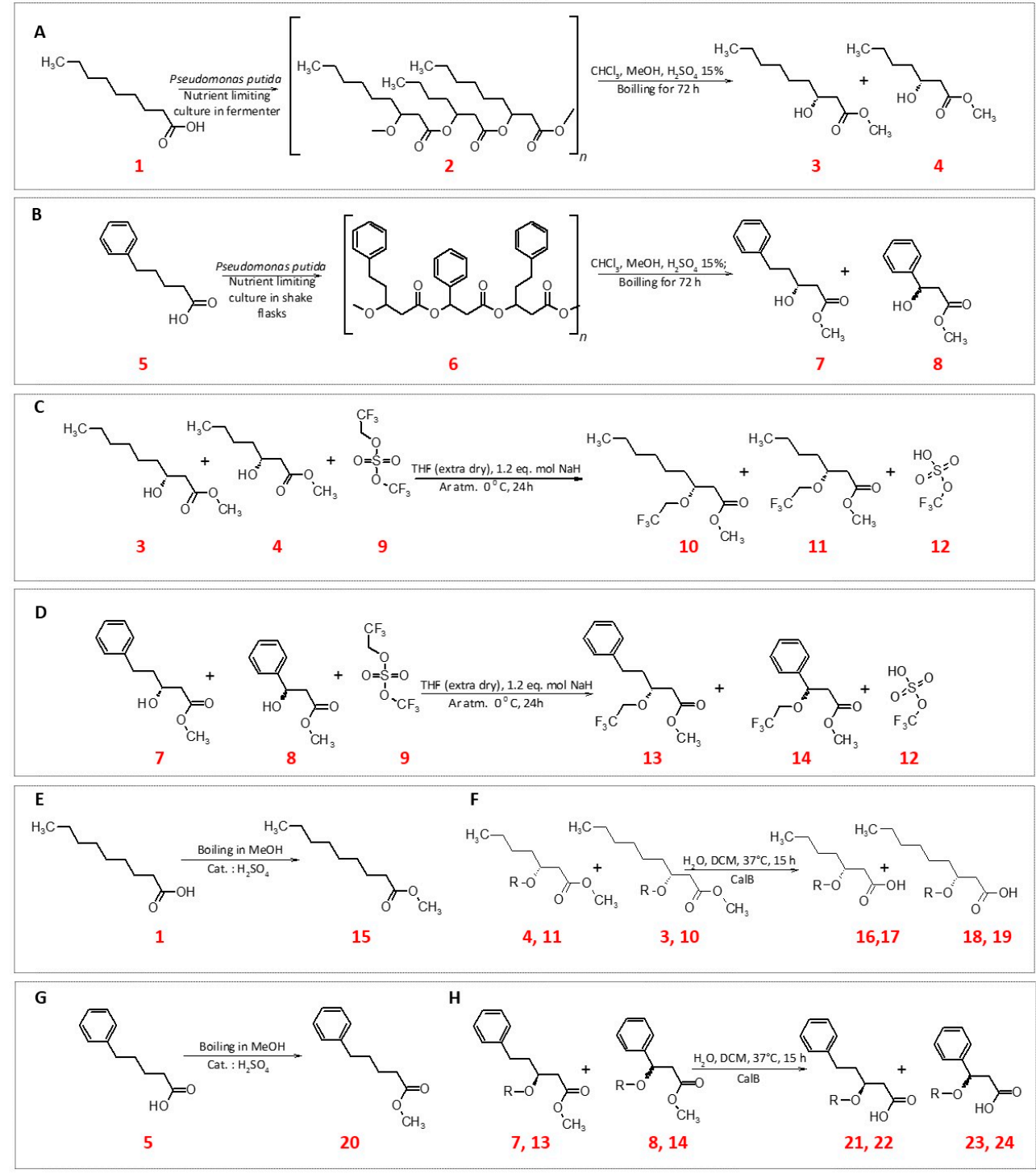

Figure 1. Scheme of synthesis PHA and modifications their monomers $(A+B: P H N$ synthesis and methanolysis; C+D: Fluorination of PHN monomers $\mathbf{E}+\mathrm{G}$ : methyl ester synthesis; $\mathbf{F}+\mathbf{H}$ : demethylation of substrates with CalB); 1. nonanoic acid; 2. poly-3-hydroxyhydroxynonaoate; 3. methyl (3R)-3-hydroxynonanoate; 4. methyl (3R)-3-hydroxyheptanoate; 5. 5-phenylpentanoic acid; 6. poly-3-hydroxypentanoate; 7. methyl (3R)-3-hydroxy-5-phenylpentanoate; 8. methyl (3R)-3-hydroxy-3-phenylpropanoate; 9. 2,2,2-trifluoroethyl trifluoromethyl sulfate; 10. methyl (3R)-3-(2,2,2-trifluoroethoxy)nonanoate; 11. methyl (3R)-3-(2,2,2-trifluoroethoxy)heptanoate; 12. trifluoromethyl hydrogen sulfate; 13. methyl (3R)-5-phenyl-3-(2,2,2-trifluoroethoxy)pentanoate; 14. methyl 3-phenyl-3-(2,2,2-trifluoroethoxy)propanoate; 15. methyl nonanoate; 16. (R)-3-hydroxyheptanoic acid; 17. 3-(2,2,2-trifluoroethoxy)heptanoic acid; 18. (R)-3-hydroxynonanoic acid; 19. 3-(2,2,2-trifluoroethoxy)nonanoic acid; 20. methyl 5-phenylpentanoate; 21. (R)-3-hydroxy-5-phenylpentanoic acid; 22. 5-phenyl-3-(2,2,2-trifluoroethoxy)pentanoic acid; 23. (R)-3-hydroxy-3-phenylpropanoic acid; 24. 3-phenyl-3-(2,2,2-trifluoroethoxy)propanoic acid. 


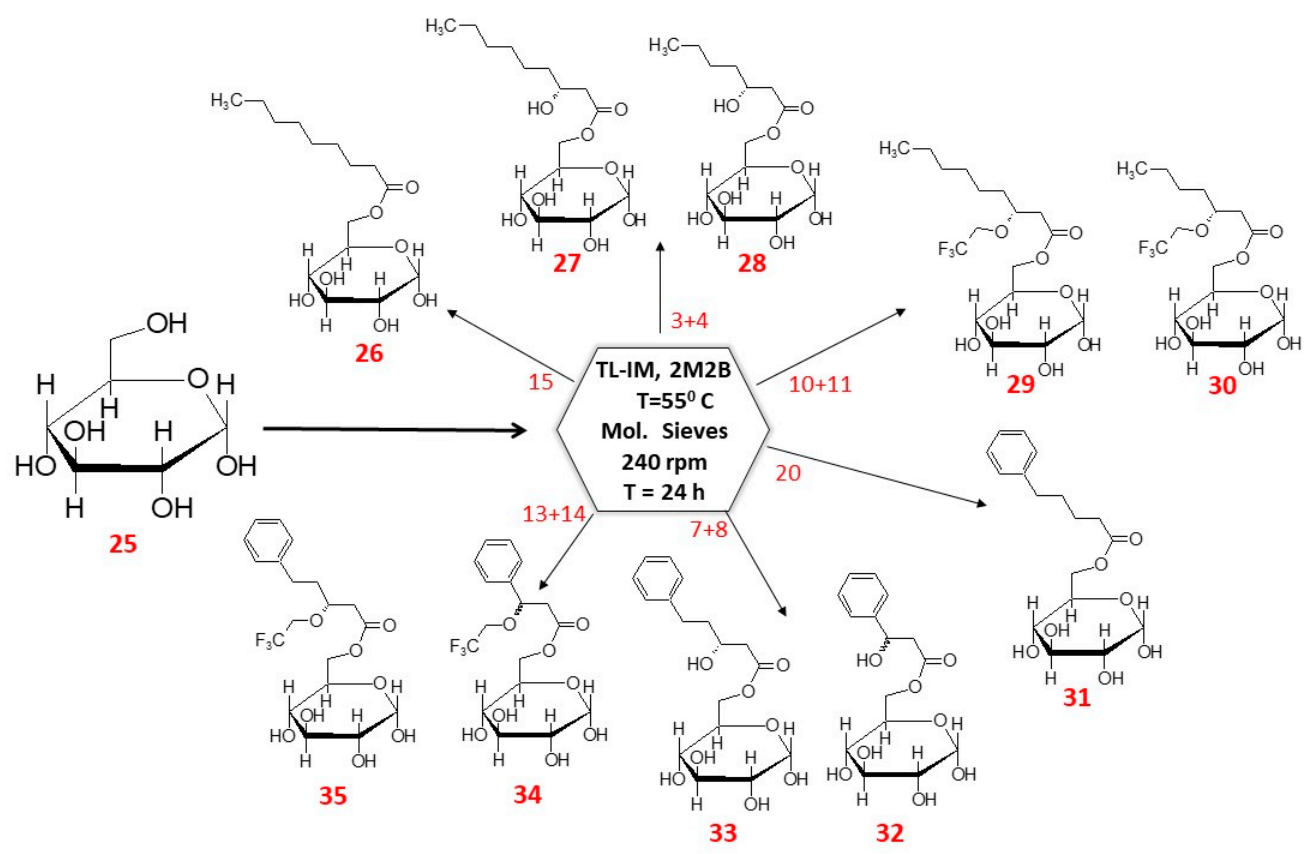

Figure 2. Scheme of synthesis SFAE. 25. Glucose [(2S,5S)-6-(hydroxymethyl) oxane-2,3,4,5-tetrol]; 26. [(3S,6S)-3,4,5,6- tetrahydroxyoxan-2-yl] methyl nonanoate]; 27. [(3S,6S)-3,4,5,6-tetrahydroxyoxan-2-yl] methyl (3R)-3-hydroxynanonoate; 28. [(3S,6S)-3,4,5,6-tetrahydroxyoxan-2-yl] methyl (3R) -3-hydroxyheptanoate; 29. [(3S,6S)-3,4,5,6-tetrahydroxyoxan-2-yl] methyl(3R)-3-(2,2,2-trifluoroethoxy) nonanoate; 30. [(3S,6S)-3,4,5,6-tetrahydroxyoxan-2-yl] methyl (3R)-3-(2,2,2-trifluoroethoxy) heptanoate; 31. [(3S,6S)-3,4,5,6-tetrahydroxyoxan-2-yl] methyl 5-phenylpentanoate; 32 . [(3S,6S)-3,4,5,6tetrahydroxyoxan-2-yl]methyl $\quad(3 R) \quad$-3-hydroxy-3-phenylpropanoate; $\quad 33 . \quad[(3 S, 6 S)-3,4,5,6-$ tetrahydroxyoxan-2-yl] methyl (3R)-3-hydroxy-5-phenylpentanoate; 34. [(3S,6S)-3,4,5,6-tetrahydroxyoxan-2-yl] methyl (3R)-3-phenyl-3-(2,2,2-trifluoroethoxy) propanoate; 35. [(3S,6S)-3,4,5,6-tetrahydroxyoxan-2-yl] methyl (3R) -3-phenyl-3-(2,2,2-trifluoroethoxy) pentanoate.

\subsection{LC-MS}

The analyses were performed by UHPLC measurements on Agilent 1290 Infinity System with automatic autosampler and MS Agilent 6460 Triple Quad Detector (Santa Clara, CA, USA) equipped with Agilent Zorbax Eclipse Plus C18 column $(2.1 \times 50 \mathrm{~mm}, 1.8 \mu \mathrm{m})$. Separations were conducted at $30{ }^{\circ} \mathrm{C}$ at in a gradient of water (A) and methanol (B) according to the eluent program $0.00 \mathrm{~min}(95 \%$ $\mathrm{A} / 5 \% \mathrm{~B})$ to $1.00 \mathrm{~min}(100 \% \mathrm{~B})$ to $3.51 \mathrm{~min}(95 \% \mathrm{~A} / 5 \% \mathrm{~B})$ to $4.50 \mathrm{~min}(95 \% \mathrm{~A} / 5 \% \mathrm{~B})$ using a flow rate of $0.4 \mathrm{~mL} \mathrm{~min}^{-1}$. The $5 \mu \mathrm{l}$ injections of samples were applied in duplicates. An MS Agilent 6460 Triple Quad tandem mass spectrometer with an Agilent Jet Stream ESI interface was used in negative ion polarization using either the Scan (MS2 scan) or Product Ion Scan modes. The optimum collision energy was $5 \mathrm{eV}$ for all of the products. Nitrogen at a flow rate of $10 \mathrm{~L} \mathrm{~min}^{-1}$ was used as the drying gas and for collision-activated dissociation. The drying gas and sheath gas temperatures were set to $350{ }^{\circ} \mathrm{C}$. The capillary voltage was set to $3500 \mathrm{~V}$, whereas the nozzle voltage was set to $500 \mathrm{~V}$. All compounds were monitored in scan and product ion modes with different collision energies (5-30 eV) $(m / z$ values of products in the Table 2). MassHunter software (Version B.05.00, Agilent, Santa Clara, CA, USA) was used for HPLC-MS system control, data acquisition, and data processing.

\subsection{Antimicrobial Testing}

The studies of antimicrobial activity were conducted for modified and non-modified PHA monomers (acids) and their SFAE derivatives using clinical and reference strains of bacteria and yeast-like fungi from international microbe collections: ATCC (American Type Culture Collection), NCTC (National Collection of Type Culture) and CIP (The Collection de l'Institut Pasteur). Among 
reference strains, there were seven Gram-positive bacteria (Staphylococcus aureus NCTC 4163, S. aureus ATCC 6538, S. epidermidis ATCC 12228, S. epidermidis ATCC 35984, Enterococcus hirae ATCC 10541, Bacillus cereus ATCC 17778 and B. subtilis ATCC 6633) and four Gram-negative bacteria (Pseudomonas aeruginosa ATCC 27853, Escherichia coli ATCC 25922, Salmonella enterica subsp. enterica CIP 108115 and clinical isolate of Listeria monocytogenes). The yeast-like fungi used in this study were Candida spp. (C. parapsilosis ATCC 22019, C. krusei ATCC 6258, C. albicans ATCC 90028 and C. albicans ATCC 10231). Compounds antimicrobial activity was expressed as minimum inhibitory concentration (MIC) according to The European Committee on Antimicrobial Susceptibility Testing (EUCAST) and The Clinical \& Laboratory Standards Institute (CLSI) reference procedures with some modification. MIC was tested by the twofold serial microdilution method (in 96-well microtiter plates) on MH II liquid medium for bacteria or RPMI- 1640 medium for Candida species. The final inoculum of all studies bacteria was $10^{60} \mathrm{CFU} / \mathrm{mL}$ (colony forming unit per $\mathrm{mL}$ ) and $5 \times 10^{4}$ to $2.5 \times 10^{5} \mathrm{CFU} \mathrm{mL}^{-1}$ for yeast. The stock solutions of tested compounds were prepared in DMSO and diluted in sterile medium (to maximum $3 \%$ of solvent content). The concentrations of compounds were from 78 to $5000 \mu \mathrm{g} \mathrm{mL}$. The MIC value was the lowest concentration of the researched compound at which bacteria growth was no longer observed after $18 \mathrm{~h}$. Yeast growth was evaluated by absorbance measurement at $530 \mathrm{~nm}$ after at least $24 \mathrm{~h}$ of incubation. The MIC was defined as a $50 \%$ or more reduction in growth compared to the control well $[38,48]$. As controls, two antimicrobial compounds were used: ciprofloxacin (antibacterial) and fluxonazole (antifungal).

\section{Conclusions}

This work provides an insight into synthesis of novel range of compounds derived from bacterial polyesters - polyhydroxyalkanoates. Firstly, we have established a methodology for protection of hydroxyl group of PHA derived monomers by introducing a fluorinated moiety via an etheric bond. Secondly, we developed a protocol for biocatalytic acylation of glucose with these bacterially derived fatty acids. Further in the study we have tested antimicrobial potential of these unmodified and modified PHA derivatives. The obtained compounds revealed moderate antibacterial and antifungal activities. Further research is needed in order to increase the antimicrobial activity of either PHA monomers or their sugar esters by introduction of other bioactive structural components to their moieties.

Supplementary Materials: The following are available online at http://www.mdpi.com/2073-4344/9/6/510/s1.

Author Contributions: Conceptualization, M.G.; Data curation, J.S.; Formal analysis, W.S.; Investigation, W.S., K.S. and J.P.; Supervision, J.S., M.S. and M.G.; Visualization, J.P.; Writing-original draft, W.S., K.S. and J.P.; Writing-review \& editing, J.S., M.S. and M.G.

Funding: This work was supported by the National Science Centre, Poland [grant SONATA no. 2015/17/D/ST4/00514]. JP and WS acknowledge the support of InterDokMed project no. POWR.03.02.00-00-I013/16. We greatly acknowledge the joint consortium "Interdisciplinary Centre of Physical, Chemical and Biological Sciences" of ICSC PAS and INP PAS for providing access to the Agilent 1290 Infinity System with an automatic autosampler and an MS Agilent 6460 Triple Quad Detector. The research on antimicrobial activity was carried out with the use of CePT infrastructure financed by the European Union-the European Regional Development Fund within the Operational Programme "Innovative economy" for 2007-2013.

Conflicts of Interest: The authors declare no conflicts of interest.

\section{References}

1. Staroń, J.; Dąbrowski, J.M.; Cichoń, E.; Guzik, M. Lactose esters: Synthesis and biotechnological applications. Crit. Rev. Biotechnol. 2018, 38, 245-258. [CrossRef] [PubMed]

2. Hidayat, C.; Fitria, K.; Hastuti, P. Enzymatic synthesis of bio-surfactant fructose oleic ester using immobilized lipase on modified hydrophobic matrix in fluidized bed reactor. Agric. Agric. Sci. Procedia 2016, 9, 353-362. [CrossRef] 
3. Jeromin, G.E.; Zoor, A.; Stergiou, P.-Y.; Foukis, A.; Filippou, M.; Koukouritaki, M.; Parapouli, M.; Theodorou, L.G.; Hatziloukas, E.; Afendra, A.; et al. Enzymatic esterification of tapioca maltodextrin fatty acid ester. Carbohydr. Polym. 2001, 99, 2079-2090.

4. Maag, H. Fatty acid derivatives: Important surfactants for household, cosmetic and industrial purposes. J. Am. Oil Chem. Soc. 1984, 61, 259-267. [CrossRef]

5. Hill, K.; Rhode, O. Sugar-based surfactants for consumer products and technical applications. Lipid/Fett 1999, 101, 25-33. [CrossRef]

6. Neta, N.D.A.S.; Santos, J.C.S.D.; Sancho, S.D.O.; Rodrigues, S.; Gonçalves, L.R.B.; Rodrigues, L.R.; Teixeira, J.A. Enzymatic synthesis of sugar esters and their potential as surface-active stabilizers of coconut milk emulsions. Food Hydrocoll. 2012, 27, 324-331. [CrossRef]

7. Zhao, T.-H.; Gu, J.-Y.; Pu, W.-F.; Dong, Z.-M.; Liu, R. Study on the synthesis and properties of an eco-friendly sugar-based anionic-nonionic surfactant. RSC Adv. 2016, 6, 70165-70173. [CrossRef]

8. El-Laithy, H.M.; Shoukry, O.; Mahran, L.G. Novel sugar esters proniosomes for transdermal delivery of vinpocetine: Preclinical and clinical studies. Eur. J. Pharm. Biopharm. 2011, 77, 43-55. [CrossRef]

9. Szuts, A.; Szabó-Révész, P. Sucrose esters as natural surfactants in drug delivery systems-A mini-review. Int. J. Pharm. 2012, 433, 1-9. [CrossRef]

10. Zhao, L.; Zhang, H.; Hao, T.; Li, S. In vitro antibacterial activities and mechanism of sugar fatty acid esters against five food-related bacteria. Food Chem. 2015, 187, 370-377. [CrossRef]

11. Xiao, D.; Ye, R.; Davidson, P.M.; Hayes, D.G.; Golden, D.A.; Zhong, Q. Sucrose monolaurate improves the efficacy of sodium hypochlorite against escherichia coli O157: H7 on spinach. Int. J. Food Microbiol. 2011, 145, 64-68. [CrossRef] [PubMed]

12. Ferla, B.L.; Lay, L.; Poletti, L.; Russo, G.; Panza, L. Easy chemo-enzymatic synthesis of human milk trisaccharides from a common selectively protected lactose building block. J. Carbohydr. Chem. 2000, 19, 331-343. [CrossRef]

13. Rencurosi, A.; Poletti, L.; Panza, L.; Lay, L. Improvement on lipase catalysed regioselective O-acylation of lactose: A convenient route to 2-O-fucosyllactose. J. Carbohydr. Chem. 2001, 20, 761-765. [CrossRef]

14. Desbois, A.P. Potential applications of antimicrobial fatty acids in medicine, agriculture and other industries. Recent Pat. Antiinfect. Drug Discov. 2012, 7, 111-122. [CrossRef] [PubMed]

15. Karlova, T.; Poláková, L.; Šmidrkal, J.; Filip, V. Antimicrobial effects of fatty acid fructose esters. Czech J. Food Sci. 2010, 28, 146-149. [CrossRef]

16. Das, B.; Sarkar, S.; Sarkar, A.; Bhattacharjee, S.; Bhattacharjee, C. Recovery of whey proteins and lactose from dairy waste: A step towards green waste management. Process Saf. Environ. Prot. 2016, 101, 27-33. [CrossRef]

17. Huang, C.B.; George, B.; Ebersole, J.L. Antimicrobial activity of n-6, n-7 and n-9 fatty acids and their esters for oral microorganisms. Arch. Oral Biol. 2010, 55, 555-560. [CrossRef]

18. Blanchfield, J.; Toth, I. Lipid, Sugar and Liposaccharide based delivery systems 2. Curr. Med. Chem. 2012, 11, 2375-2382. [CrossRef]

19. Zheng, C.J.; Yoo, J.S.; Lee, T.G.; Cho, H.Y.; Kim, Y.H.; Kim, W.G. Fatty acid synthesis is a target for antibacterial activity of unsaturated fatty acids. FEBS Lett. 2005, 579, 5157-5162. [CrossRef]

20. Smith, A.; Nobmann, P.; Henehan, G.; Bourke, P.; Dunne, J. Synthesis and antimicrobial evaluation of carbohydrate and polyhydroxylated non-carbohydrate fatty acid ester and ether derivatives. Carbohydr. Res. 2008, 343, 2557-2566. [CrossRef]

21. Watanabe, T.; Katayama, S.; Matsubara, M.; Honda, Y.; Kuwahara, M. Antibacterial carbohydrate monoesters suppressing cell growth of streptococcus mutans in the presence of sucrose. Curr. Microbiol. 2000, 41, $210-213$. [CrossRef] [PubMed]

22. Galbraith, H.; Miller, T.B. Effect of metal cations and PH on the antibacterial activity and uptake of long chain fatty acids. J. Appl. Bacteriol. 1973, 36, 635-646. [CrossRef] [PubMed]

23. Fernandez-Lorente, G.; Palomo, J.M.; Cocca, J.; Mateo, C.; Moro, P.; Terreni, M.; Fernandez-Lafuente, R.; Guisan, J.M. Regio-selective deprotection of peracetylated sugars via lipase hydrolysis. Tetrahedron 2003, 59, 5705-5711. [CrossRef]

24. Dembitsky, V.M.; Srebnik, M. Natural halogenated fatty acids: Their analogues and derivatives. Prog. Lipid Res. 2002, 41, 315-367. [CrossRef] 
25. Andreu, C.; Marcel, Æ.; Varea, T.; Diaz, D.; Asensio, G. The introduction of fluorine atoms or trifluoromethyl groups in short cationic peptides enhances their antimicrobial activity. Bioorgan. Med. Chem. 2006, 14, 6971-6978.

26. Hiyama, T.; Yamamoto, H. Biologically active organofluorine compounds. In Organofluorine Compounds; Springer: Berlin/Heidelberg, Germany, 2012; pp. 137-182.

27. Isanbor, C.; Hagan, D.O. Fluorine in medicinal chemistry: A review of anti-cancer agents §. J. Fluor. Chem. 2006, 127, 303-319. [CrossRef]

28. Cheeseman, K.H.; Albano, E.F.; Tomasi, A.; Slater, T.F. Biochemical studies on the metabolic activation of halogenated alkanes. Environ. Health Perspect. 1985, 64, 85-101. [CrossRef]

29. Belli, W.A.; Buckley, D.H.; Marquis, R.E. Weak acid effects and fluoride inhibition of glycolysis by streptococcus mutans GS-5. Can. J. Microbiol. 1992, 41, 785-791. [CrossRef]

30. Suriyamongkol, P.; Weselake, R.; Narine, S.; Moloney, M.; Shah, S. Biotechnological approaches for the production of polyhydroxyalkanoates in microorganisms and plants-A review. Biotechnol. Adv. 2007, 25, 148-175. [CrossRef]

31. Abe, H.; Doi, Y. Side-Chain effect of second monomer units on crystalline morphology thermal properties and enzymatic degradability for random copolyesters of (R) -3-hydroxybutyric acid with (R) -3-hydroxyalkanoic acids. Biomacromolecules 2002, 3, 133-138. [CrossRef]

32. Madison, L.; Huisman, G. Metabolic engineering of poly(3-hydroxyalkanoates): From DNA to plastic. Microbiol. Mol. Biol. Rev. 1999, 63, 21-53. [PubMed]

33. O'Connor, S.; Szwej, E.; Nikodinovic-Runic, J.; O'Connor, A.; Byrne, A.T.; Devocelle, M.; O’Donovan, N.; Gallagher, W.M.; Babu, R.; Kenny, S.T.; et al. The anti-cancer activity of a cationic anti-microbial peptide derived from monomers of polyhydroxyalkanoate. Biomaterials 2013, 34, 2710-2718. [CrossRef] [PubMed]

34. Radivojevic, J.; Skaro, S.; Senerovic, L.; Vasiljevic, B.; Guzik, M.; Kenny, S.T.; Maslak, V.; Nikodinovic-Runic, J.; O'Connor, K.E.; O'Connor, K. Polyhydroxyalkanoate-based 3-hydroxyoctanoic acid and its derivatives as a platform of bioactive compounds. Appl. Microbiol. Biotechnol. 2015, 100, 161-172. [CrossRef] [PubMed]

35. Constantin, M.; Simionescu, C.I.; Carpov, A.; Samain, E.; Driguez, H. Chemical modification of poly (hydroxyalkanoates). Copolymers bearing pendant sugars. Macromol. Rapid Commun. 1999, 94, 91-94. [CrossRef]

36. Walsh, M.K.; Bombyk, R.A.; Wagh, A.; Bingham, A.; Berreau, L.M. Synthesis of lactose monolaurate as influenced by various lipases and solvents. J. Mol. Catal. B Enzym. 2009, 60, 171-177. [CrossRef]

37. Plou, F.J.; Cruces, M.A.; Ferrer, M.; Fuentes, G.; Pastor, E.; Bernabé, M.; Christensen, M.; Comelles, F.; Parra, J.L.; Ballesteros, A. Enzymatic acylation of di- and trisaccharides with fatty acids: Choosing the appropriate enzyme, support and solvent. J. Biotechnol. 2002, 96, 55-66. [CrossRef]

38. Clinical and Laboratory Standards Institute (CLSI); Weinstein, M.P. Methods for Dilution Antimicrobial Susceptibility Tests for Bacteria That Grow Aerobically, 9th ed.; Clinical and Laboratory Standards Institute: Wayne, NY, USA, 2012.

39. Kümmerer, K. Antibiotics in the aquatic environment-A. review-Part I. Chemosphere 2009, 75, 417-434. [CrossRef]

40. Wagh, A.; Walsh, M.K.; Martini, S. Effect of lactose monolaurate and high intensity ultrasound on crystallization behavior of anhydrous milk fat. J. Am. Oil Chem. Soc. 2012, 90, 977-987. [CrossRef]

41. Lucarini, S.; Fagioli, L.; Campana, R.; Cole, H.; Duranti, A.; Baffone, W.; Vllasaliu, D.; Casettari, L. Unsaturated fatty acids lactose esters: cytotoxicity, permeability enhancement and antimicrobial activity. Eur. J. Pharm. Biopharm. 2016, 107, 88-96. [CrossRef]

42. Bills, G.; Cueva, C.; Moreno-arribas, M.V.; Martı, P.J.; Vicente, M.F.; Basilio, A.; Rodr1, J.M. Antimicrobial activity of phenolic acids against commensal, probiotic and pathogenic bacteria. Res. Microbiol. 2010, 161, 372-382.

43. Pohl, C.H.; Kock, J.L.F.; Thibane, V.S. Antifungal free fatty acids: A review antifungal free fatty acids: A review. Sci. Microb. Pathog. Curr. Res. Technol. Adv. 2011, 1, 61-71.

44. Sandoval, Á.; Arias-Barrau, E.; Bermejo, F.; Cañedo, L.; Naharro, G.; Olivera, E.R.; Luengo, J.M. Production of 3-hydroxy-n-phenylalkanoic acids by a genetically engineered strain of Pseudomonas putida. Appl. Microbiol. Biotechnol. 2005, 67, 97-105. [CrossRef] [PubMed] 
45. Ferrer, M.; Soliveri, J.; Plou, F.J.; López-Cortés, N.; Reyes-Duarte, D.; Christensen, M.; Copa-Patiño, J.L.; Ballesteros, A. Synthesis of sugar esters in solvent mixtures by lipases from Thermomyces lanuginosus and Candida antarctica B, and their antimicrobial properties. Enzyme Microb. Technol. 2005, 36, 391-398. [CrossRef]

46. Sofińska, K.; Barbasz, J.; Witko, T.; Dryzek, J.; Haraźna, K.; Witko, M.; Kryściak-Czerwenka, J.; Guzik, M. Structural, Topographical, and Mechanical characteristics of purified polyhydroxyoctanoate polymer. J. Appl. Polym. Sci. 2019, 136, 47192. [CrossRef]

47. Siebenhaller, S.; Gentes, J.; Infantes, A.; Muhle-Goll, C.; Kirschhöfer, F.; Brenner-Weiß, G.; Ochsenreither, K.; Syldatk, C. Lipase-Catalyzed Synthesis of Sugar Esters in Honey and Agave Syrup. Front. Chem. 2018, 6, 1-9. [CrossRef]

48. Arendrup, M.C.; Meletiadis, J.; Mouton, J.W.; Lagrou, K.; Hamal, P.; Guinea, J. Subcommittee on Antifungal Susceptibility Testing of the ESCMID European Committee for Antimicrobial Susceptibility Testing. 2017 EUCAST Definitive Document E.DEF 9.3.1: Method for the Determination of Broth Dilution Minimum Inhibitory Concentrations of Antifungal Agents for Conidia Forming Moulds. Available online: http://www.eucast.org/fileadmin/src/media/PDFs/EUCAST_files/AFST/Files/EUCAST_E_Def_9_ 3_1_Mould_testing_definitive.pdf (accessed on 25 April 2019).

(C) 2019 by the authors. Licensee MDPI, Basel, Switzerland. This article is an open access article distributed under the terms and conditions of the Creative Commons Attribution (CC BY) license (http://creativecommons.org/licenses/by/4.0/). 